\title{
Mindfulness and related factors among addicted adolescents
}

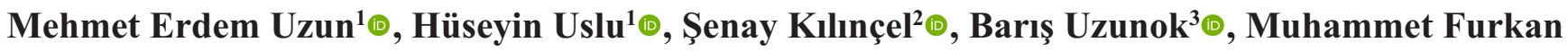 \\ Korkmaz $^{4} \oplus$, Hande Şirin ${ }^{1} \odot$
}

${ }^{1}$ Department of Child Psychiatry, University of Health Sciences, Bursa Yüksek Ihtisas Training and Research Hospital, Bursa, Turkey

${ }^{2}$ Department of Child Psychiatry, Sakarya University Training and Research Hospital, Sakarya, Turkey

${ }^{3}$ Department of Physiology, Uşak University School of Medicine, Uşak, Turkey

${ }^{4}$ Department of Pediatrics, University of Health Sciences, Bursa Yüksek Ihtisas Training and Research Hospital, Bursa, Turkey

\begin{abstract}
Objectives: Mindfulness has been defined as "the clear and single-minded awareness of what happens to us and in us, at the successive moments of perception". Mindfulness-based therapies have been used in the treatment of psychiatric diseases in recent years. There is no study on the mindfulness of addicted adolescents in our country. In this study, we aimed to determine the level of the mindfulness and the factors affecting the mindfulness among addicted adolescents.

Methods: Fourty drug-addicted adolescents and fourty five healthy adolescents were included in the study. Sociodemographic Data Form, Addiction Profile Index Adolescent Form (BAPI-E), Mindful Attention Awareness Scale (MAAS), Coping Orientation to Problems Experienced (COPE), Metacognition Questionnaire for Children and Adolescents (MCQ-C) and Child-Adolescent Social Support Scale (CASS) were applied to the participants. Clinical interviews (based on DSM-V) were performed to assess addiction.

Results: There were no significant differences in the mindfulness levels between the addicted and the nonaddicted groups. The mindfulness levels of the patients who attempted suicide were lower than the patients who did not attempt suicide. Behavioral disengagement sub-scales of COPE were significantly higher in the substance use and the denial group.
\end{abstract}

Conclusions: Non-functional styles coping with stress were found to be significantly higher in the addicted group, however, we found no significant differences in the mindfulness levels.

Keywords: Mindfulness, adolescents, substance use, addiction

$\mathrm{T}$ he word meaning of the Turkish equivalent of conscious mindfulness is expressed as a "state of deep awareness". Conscious mindfulness, which originates from Buddhism, is defined as "focusing only on what is now, without judgment "[1]. Mindfulness is a mind and the body activity that involves focusing attention on instant lives and observing inner experiences. The concept of Mindfulness originated from meditations practiced in the East. In this practice called mindfulness meditation, attention constantly pay attention to breathing, body feelings, emotions, or the mind's flow; that is, thoughts. All these inner experiences are observed through nonjudgmental acceptance. Mindfulness (mindfulness) is a non-pharmacological Mind-Body Therapy that first presented by KabatZinn to the medical community in the MindfulnessBased Stress Reduction Program. Kabat-Zinn explained the term mindfulness simply as "revealing 
past experiences step by step without judgment and paying attention to the present purpose" [2].

Mindfulness has attracted considerable attention in behavioral medicine and psychiatric literature over the past 20 years. As a result, multiple mindfulness meditation has been designed to treat many diseases and conditions [3]. Although studies have shown that mindfulness reduces psychological problems in many patient populations, it is unclear how mindfulness causes that $[1,3,4]$.

The number of research conducted on mindfulness in Turkey is very limited. When the literature is reviewed, we see that mindfulness studies conducted in the field of alcohol and substance addiction generally focus on using the mindfulness therapy for addiction [5].

In our country's literature, the mindfulness levels of addicts for the adult group were examined, and we did not find a study on the mindfulness in adolescents. This study aims to examine the level of mindfulness and related factors in adolescents with substance use disorder.

\section{METHODS}

The study sample was composed of patients who were followed up in the Child and Adolescent Substance Addiction Treatment Center (ÇEMATEM According to DSM-V. The patients consisted of 40 adolescents with substance use disorders. The patient group's diagnoses were made by a child psychiatrist using a semi-structured interview that was created by us, taking into account the DSM-V Drug Use Disorders diagnostic criteria. The study's control group was composed of 45 adolescents from a high school in the city center who had similar characteristics in the terms of socioeconomic level, age and gender, with no substance use disorder and no psychopathology due to the clinical evaluation. The Clinical Research Evaluation Committee gave the ethics committee approval of the study. (Decision date / No: 14.01.2015 / 2047848626).

\section{Personal Information Form}

This form, which contains 12 questions, was created by researchers and is intended to learn the sociodemographic characteristics of participants.
Addiction Profile Index Adolescent Form (BAPIE)

BAPI-E was developed in 2012 by Ögel et al. [6] to evaluate the extent of addiction and measure the severity of addiction in the 15-18 age group adolescents. The scale consists of 25 items and includes five sub-dimensions: substance use characteristics, diagnostic criteria, effects on life, cravings and motivation. The response options are a quintet Likert-type scale, ranging from "ever, just 1-2 times, 1-3 times a month, 1-5 times a week and every day". In the scale's validity and reliability study, the Cronbach alpha coefficient was determined as 0.87 and the cut-off point as 2 . In this study, the Cronbach alpha coefficient of the scale was calculated as 0.96 .

\section{Mindful Attention Awareness Scale (MAAS)}

The MAAS is designed to measure the attention and the mindfulness, focusing on the present. The MAAS is a 6-point Likert-type scale consisting of 15 items. Each item is scored between 1 (almost always) and 6 (almost never). Internal consistency was found to be $\alpha=0.82(\mathrm{~s}=327)$ in the student sample and $\alpha=$ $0.87(\mathrm{~s}=239)$ in the general adult sample. MAAS's test-retest results are also quite high $(\mathrm{r}=0.81)$. Internal consistency $\alpha=0.78(\mathrm{~s}=100)$, test-retest result 0.83 $(\mathrm{s}=78)$, internal consistency $\alpha=0.80,(\mathrm{~s}=78)$ and test-retest correlation result 0.86 were found in the adult sample studies [5].

\section{Coping Orientation to Problems Experienced (COPE)}

The scale developed by Carver et al. is a self-report scale consisting of 60 questions and 15 subscales and each subscale consists of four questions. Each of these subscales gives information about a different coping attitude. As a result, the height of the subscales' scores provides the possibility to comment on which coping attitude is more used by the person [7].

\section{Metacognition Scale Child and Adolescent Form (MCQ-C)}

The child and adolescent form of the upper cognition scale was developed by Bacow et al. [8] in 2009 and the original name of the scale is "Meta-Cognitions Questionnaire for Children (MCQ-C)". Each item in the MCQ-C is answered on a four-unit Likert-type Rating Scale with “(1) absolutely disagree" and "(4) 
absolutely agree" ends. The scores that can be taken from the scale range from 24 to 96 and the rise of the score indicates an increase in negative upper cognitive activity. Sub factors and items covered; positive parent concerns $(1,7,9,16,20,23)$, negative parent concerns $(2,4,8,10,13,18)$, superstitions, punishment and responsibility beliefs $(6,12,17,19,21,22)$ and cognitive monitoring $(3,5,11,14,15,24)$ [9].

\section{Social Support Assessment Scale for Children (CASS)}

The scale developed by Dubow and Ullman in 1989 aimed to assess students ' perceptions of the social support they receive from their families, friends, and teachers. On a quintet Likert-type scale, each item gets 1, 2, 3, 4, 5 points. Scale items are grouped into three sub-groups: friend Support (19 items), Family Support (12 items), teacher support (10 items). The score that can be taken from the scale is 41-205. The validity and reliability of the scale in our country was carried out by Gökler [10] in 2007.

\section{Statistical Analysis}

The data was examined by the Shapiro Wilk test whether or not it presents normal distribution. Descriptive statistics are given as mean, standard deviation, frequency, and percentage. Independent samples t-test was used to compare two independent groups for normally distributed data. Pearson Chi-square test, Fisher's Exact Chi-square test, and Fisher-Freeman-
Halton test were used to analyze categorical data. The statistical significance level was determined as $\alpha=$ 0.05 . Statistical analyses were performed with IBM SPSS ver.23.0 (IBM Corp. Released 2015. IBM SPSS Statistics for Windows, Version 23.0. Armonk, NY: IBM Corp.).

\section{RESULTS}

The sample's sociodemographic characteristics taken in the study are shown in the Table (Table 1). In the study, 40 adolescents were in the substance use disorder group and 45 adolescents were in the healthy group. No statistically significant difference was found between the patient and healthy groups in terms of age, gender, education level of the parents, the family's income level, place of residence, and presence of chronic physical disease $(p>0.05)$.

On the BAPI-E scale in the group with substance use disorder; substance use characteristics $1.71 \pm 0.63$, diagnosis $7.4 \pm 1.74$, effects on life $7.45 \pm 2.40$, cravings $1.28 \pm 0.78$, motivation $1.7 \pm 0.56$ and it was found to be $6.69 \pm 1.49$ in total.

There was no significant difference between the two groups in terms of MAAS mean scores, MCQ-C total and subscale total scores, COPE problem-oriented coping subscale scores, and COPE emotionallyoriented coping subscale scores. A significant difference was found between the scores obtained by

\section{Table 1. Comparison of sociodemographic characteristics between groups}

\begin{tabular}{lccc}
\hline Variables & $\begin{array}{c}\text { Group without } \\
\text { substance use disorder } \\
(\mathbf{n = 4 5 )} \\
\mathbf{n}(\mathbf{\%})\end{array}$ & $\begin{array}{c}\text { Group with substance } \\
\text { use disorder } \\
(\mathbf{n}=\mathbf{4 0}) \\
\mathbf{n}(\mathbf{\%})\end{array}$ & $p$ value \\
\hline Age (years) (mean \pm SD) & $16.51 \pm 0.80$ & $16.50 \pm 0.95$ & $0.972^{\text {a }}$ \\
\hline Gender (man) & $36(80 \%)$ & $34(85 \%)$ & $0.546^{\text {b }}$ \\
\hline Psychiatric ilness in the family (yes) & $2(4.4 \%)$ & $12(30 \%)$ & $\mathbf{0 . 0 0 2}^{\mathbf{b}}$ \\
Alcohol use in the family (yes) & $8(17.8 \%)$ & $24(60 \%)$ & $<\mathbf{0 . 0 0 1}^{\mathbf{b}}$ \\
Previous psychiatric treatment (yes) & $5(11.1 \%)$ & $26(65 \%)$ & $<\mathbf{0 . 0 0 1}^{\mathbf{b}}$ \\
Suicide attempt (yes) & $0(0 \%)$ & $9(22.5 \%)$ & $\mathbf{0 . 0 0 1}^{\mathbf{c}}$ \\
\hline Smoking (yes) & $21(46.7 \%)$ & $38(95 \%)$ & $<\mathbf{0 . 0 0 1}^{\mathbf{b}}$ \\
Alcohol use (yes) & $10(22.2 \%)$ & $37(92.5 \%)$ & $<\mathbf{0 . 0 0 1}^{\mathbf{b}}$ \\
\hline
\end{tabular}

$\mathrm{SD}=$ standard deviation

${ }^{a}$ t test, ${ }^{b}$ Pearson's chi-square test, ${ }^{c}$ Fisher's exact chi-square test 
Table 2. Comparison of total scale scores between groups

\begin{tabular}{lccc}
\hline & $\begin{array}{c}\text { Group without } \\
\text { substance use disorder } \\
(\mathbf{n}=\mathbf{4 5}) \\
(\mathbf{m e a n} \pm \mathbf{S D})\end{array}$ & $\begin{array}{c}\text { Group with substance } \\
\text { use disorder } \\
(\mathbf{n}=\mathbf{4 0})\end{array}$ & p value* \\
$(\mathbf{m e a n} \pm \mathbf{S D})$ & \\
\hline MAAS total & $53.69 \pm 13.92$ & $49.4 \pm 11.52$ & 0.146 \\
MCQ-C positive top concerns & $13.00 \pm 3.98$ & $13.65 \pm 4.14$ & 0.463 \\
MCQ-C negative top concerns & $16.27 \pm 4.33$ & $16.38 \pm 4.31$ & 0.909 \\
MCQ-C superstition punishment and & $16.36 \pm 4.21$ & $16.4 \pm 4.95$ & 0.964 \\
responsibility & $17.96 \pm 3.57$ & $15.65 \pm 4.29$ & $\mathbf{0 . 0 0 8}$ \\
MCQ-C cognitive monitoring & $63.58 \pm 9.12$ & $62.08 \pm 13.51$ & 0.555 \\
MCQ-C total & $13.61 \pm 2.15$ & $12.58 \pm 2.89$ & 0.083 \\
COPE problem-focused coping & $13.38 \pm 1.84$ & $12.99 \pm 2.65$ & 0.466 \\
COPE emotionally focused coping & $10.15 \pm 1.79$ & $12.11 \pm 2.63$ & $<\mathbf{0 . 0 0 1}$ \\
COPE dysfunctional coping & $2.97 \pm 0.43$ & $2.83 \pm 0.45$ & 0.181 \\
CASS friend Support & $3.21 \pm 0.24$ & $3.1 \pm 0.44$ & 0.207 \\
CASS family Support & $2.6 \pm 0.49$ & $2.47 \pm 0.55$ & 0.291 \\
\hline CASS teacher Support & $8.77 \pm 0.90$ & $8.40 \pm 1.07$ & 0.113 \\
\hline CASS total & & & \\
\hline
\end{tabular}

MAAS = Mindful Attention Awareness Scale, MCQ-C = Metacognition Questionnaire for Children and Adolescents, COPE

$=$ Coping Orientation to Problems Experienced, CASS =Child-Adolescent Social Support Scale $(\mathrm{CASS}), \mathrm{SD}=\mathrm{standard}$ deviation

*t test

patients and control groups from the "COPE dysfunctional coping subscales " $(p<0.05)$ (Table2).

When the groups with and without substance use disorder were compared in terms of COPE substances, there were statistically significant differences in planning, positive reinterpretation and development, emotional social support use, behavioral disengagement and substance use and denial scores. It was found that the patient group scored lower than the healthy group in terms of planning, positive reinterpretation and development and the use of social-emotional support. The group's score with substance use disorder in terms of behavioral disengagement, substance use and denial was higher than the group without substance use disorder (Table 3).

A significant difference was found in the patients according to the gender in terms of suppression of other occupations, positive reinterpretation and development, use of emotional-social support and COPE problem-focused coping score scale scores $(p<0.05)$. Scale scores of girls were found to be lower than boys.
There is no difference between other scale scores in terms of gender $(p>0.05)$.

A statistically significant difference was found between the patients who attempted suicide and those who did not, only in terms of the MAAS score $(p<$ 0.05). MAAS scores of those who attempted suicide were found to be lower. A moderately negative correlation was found between the MAAS and the MCQ-C positive higher concerns. A moderate positive correlation was found between the positive upper anxieties subscale of the MCQ-C and the backward, planning, acceptance, problem-focused coping, emotionally focused coping and dysfunctional coping subscales of COPE. A moderate positive correlation was found between the MCQ-C cognitive monitoring subscale and COPE's plan-making substance. There was a moderately positive relationship between the MCQ-C's total score and the plan-making clause of COPE.

COPE was found to have a moderately positive relationship between active coping, holding back, making plans, using useful social support, suppressing 
Table 3. Comparison of people with and without substance use disorders in terms of coping attitude substances

\begin{tabular}{|c|c|c|c|}
\hline COPE sub items & $\begin{array}{l}\text { Group without substance } \\
\text { use disorder } \\
(\mathbf{n}=45) \\
(\text { mean } \pm \text { SD) }\end{array}$ & $\begin{array}{l}\text { Group with substance } \\
\text { use disorder } \\
(\mathbf{n}=\mathbf{4 0}) \\
\text { (mean } \pm \text { SD) }\end{array}$ & $p$ value* \\
\hline Active coping & $2.90 \pm 0.64$ & $2.78 \pm 0.73$ & 0.446 \\
\hline Restraint & $2.42 \pm 0.58$ & $2.51 \pm 0.77$ & 0.576 \\
\hline Planing & $3.09 \pm 0.60$ & $2.46 \pm 0.69$ & $<0.001$ \\
\hline Use of instrumental social support & $2.65 \pm 0.83$ & $2.41 \pm 0.88$ & 0.228 \\
\hline Suppressing of competing activities & $2.55 \pm 0.59$ & $2.42 \pm 0.57$ & 0.334 \\
\hline Positive reinterpretation and growth & $3.31 \pm 0.49$ & $2.74 \pm 0.65$ & $<0.001$ \\
\hline Religious coping & $2.91 \pm 0.82$ & $3.20 \pm 0.80$ & 0.124 \\
\hline Humor & $2.13 \pm 0.86$ & $2.29 \pm 0.86$ & 0.397 \\
\hline Use of emotional social support & $2.74 \pm 0.73$ & $2.33 \pm 0.69$ & 0.01 \\
\hline Acceptance & $2.29 \pm 0.75$ & $2.42 \pm 0.66$ & 0.434 \\
\hline Behavioral disengagement & $1.56 \pm 0.53$ & $1.91 \pm 0.71$ & 0.018 \\
\hline Substance use & $1.59 \pm 0.97$ & $2.91 \pm 0.90$ & $<0.001$ \\
\hline Denial & $1.72 \pm 0.58$ & $2.26 \pm 0.84$ & 0.002 \\
\hline Mental disengagement & $2.54 \pm 0.59$ & $2.51 \pm 0.57$ & 0.792 \\
\hline Focusing on and venting of emotions & $2.74 \pm 0.75$ & $2.53 \pm 0.77$ & 0.228 \\
\hline
\end{tabular}

$\mathrm{COPE}=$ Coping Orientation to Problems Experienced, $\mathrm{SD}=$ standard deviation

*t test

other preoccupations, acceptance, denial, problem-oriented coping, emotional-oriented coping, non-functional coping subscales and teacher support. A moderate positive relationship was found in COPE between the useful social support, religious coping, emotional-social support, acceptance and problem-focused coping subscales and the friend support subscale. A strong positive relationship was found with emotionally focused coping. A moderately positive correlation was found between the motivation of BAPI-E and the withdrawal of COPE. A positive correlation was found between the BAPI-E total score and the withdrawal subscale of COPE. A positive correlation was found between useful social support, positive reinterpretation, emotional-social support, sub-scales of COPE and all subscales of CASS. A moderate and positive correlation was found between CASS total scale score and COPE with positive reinterpretation, emotionalsocial support, problem-focused coping and emotionally focused coping.

\section{DISCUSSION}

Our study investigated the mindfulness levels of adolescents with the substance use disorder and the factors affecting it. Simultaneously, there was no difference in mindfulness levels, perceived social support and metacognition in adolescents with and without substance use disorder. Differences were found in ways of coping with stress. It was found that patients mainly use dysfunctional coping methods more.

However, it was found that metacognitive monitoring decreased in addicted adolescents. Besides, it was also found that planning, emotional-social support use, positive reinterpretation and development characteristics among stress-coping attitudes decreased in adolescents with substance use disorder. The mindfulness levels of the patients who have attempted suicide are lower than those who have not attempted suicide.

When we look at the literature, there is no other study examining the level of the conscious mindfulness in adolescents with the substance use disorder in 
our country. A 2014 study by Ögel et al. in adults showed that mindfulness levels in substance-using individuals were the same as in the control group and were similar to our study [1]. In the same study, it was stated that these patients might benefit from mindfulness-based therapies due to factors affecting mindfulness [5]. Shapiro et al. [11] in people with an increased level of conscious mindfulness, observed that substance use, depressive relapses, and stress levels decreased, immune system functions, empathy skills, motivation, and awareness of emotions increased. Bowen et al. [12] in a 2010 study, it was determined that the use of conscious mindfulness in the treatment of substance abuse is an effective method of bringing warmth and flexibility to the program as well as creating an area that supports discovery and development. In 2014, Robinson et al. [13] found that those with a high level of conscious mindfulness were associated with a low likelihood of lifetime alcohol or marijuana use. In the study conducted by Dabaghi et al. [14] in 2016; With the multidimensional prevention program designed to prevent substance use by adolescents, it has been proved that life skills (coping with stress, decision making, self-awareness), the individual's need to protect his body and positive attitudes towards substance use decrease, and as a result, it has been proved to be effective in preventing substance addiction. In two different studies conducted in 2006, it was found that impulsivity, problems with upper cognition and conscious suppression of thoughts were more significant in the addicted group. All these factors have been linked to low mindfulness levels in other studies [15, 16].

In the studies that examined the relationship between the mindfulness levels of drug addicts and suicide attempts, it was found that $25 \%$ of people with suicide attempts had alcohol abuse or substance abuse $[17,18]$. Suicide rates have been shown to increase in direct proportion in countries with increased alcohol use [19]. In our study, parallel with the literature, mindfulness levels of the patients with substance use disorder and suicide attempts in their past were lower than those who did not have suicide attempts in their past.

In the studies in the literature, in adolescents with substance use disorder; emotionally focused coping styles are a risk factor; problem-focused coping styles;
It has been reported to be protective for alcohol addiction, depression and suicide attempts [20,21]. Our study also supports the literature; A moderate and positive correlation was found between emotional-social support use, problem-focused coping and emotionally focused coping.

\section{Limitations}

There are some limitations in our study. The small number of the sample, the parents' educational status, the economic status, the educational status of the adolescent make it difficult to generalize. Since the drugs used by the patients during the study were not evaluated, their relationship with clinical evaluation scales and cognitive functions could not be examined.

\section{CONCLUSION}

As a result, substance use disorder is an increasing public health problem. We think that the application of therapies that will increase the level of conscious mindfulness, ways of coping with stress (especially functional coping methods), planning, use of emotional-social support, positive reinterpretation and improvement of development characteristics may be more effective in the treatment of substance use disorder. We believe that the number of psychological, biological and treatment effectiveness studies investigating the level of mindfulness of substance use among adolescents should increase.

\section{Authors' Contribution}

Study Conception: MEU; Study Design: MEU; Supervision: MEU; Funding: MEU; Materials: MEU; Data Collection and/or Processing: HU; Statistical Analysis and/or Data Interpretation: HŞ; Literature Review: BU; Manuscript Preparation: HŞ, ŞK and Critical Review: MFK.

\section{Conflict of interest}

The authors disclosed no conflict of interest during the preparation or publication of this manuscript.

\section{Financing}

The authors disclosed that they did not receive any grant during the conduction or writing of this study. 


\section{REFERENCES}

1. Brown KW, Ryan RM. The benefits of being present: mindfulness and its role in psychological well-being. J Pers Soc Psychol 2003;84:822-48.

2. Kabat-Zinn J. Full catastrophe living: using the wisdom of your body and mind to face stress, pain, and illness. New York, NY: Random House, Inc.; 1990.

3. Baer RA. Mindfulness training as a clinical intervention: a conceptual and empirical review. Clin Psychol Sci Prac 2003;10:12543.

4. Creswell JD, Way BM, Eisenberger NI, Lieberman MD. Neural correlates of dispositional mindfulness during affect labeling. Psychosomatic Medicine 2007;69:560-5.

5. Ögel K, Sarp N, Gürol DT, Ermağan E. [Investigation of mindfulness and affecting factors of mindfulness among substance users and non users]. Anadolu Psikiyatri Derg 2014;15:282-8. [Article in Turkish]

6. Ögel K, Karadayi G, Senyuva G, Hatipoglu S. [Development of the addiction profile index adolescent form (BAPI-E)]. Klinik Psikofarmakoloji Bülteni 2012;22:109. [Article in Turkish]

7. Ağargün MY, Beşiroğlu L, Kıran ÜK, Özer ÖA, Kara H. [The psychometric properties of the COPE inventory in Turkish sample: a preliminary research]. Anadolu Psikiyatr Derg 2005;6:2216. [Article in Turkish]

8. Bacow TL, Pincus DB, Ehrenreich JT, Brody LR. The metacognitions questionnaire for children: Development and validation in a clinical sample of children and adolescents with anxiety disorders. J Anxiety Disord 2009;23:727-36.

9. Irak M. [Standardization of Turkish form of metacognition questionnaire for children and adolescents: the relationships with anxiety and obsessive-compulsive symptoms]. Türk Psikiyatri Dergisi 2012;23:47-54. [Article in Turkish]

10. Gökler I. [The Turkish adaptation study of social support appraisals scale to be used with children and adolescents: factor structure, validity and reliability]. Çocuk ve Gençlik Ruh Sağlığı Dergisi 2007;14:90-9. [Article in Turkish]

11. Shapiro SL, Brown KW, Biegel GM. Teaching self-care to caregivers: effects of mindfulness-based stress reduction on the mental health of therapists in training. Train Educ Prof Psychol 2007;1:105-15.

12. Bowen S, Chawla N, Marlatt GA. Mindfulness-based relapse prevention for addictive behaviors. J Consult Clin Psychol 2010;78:362-74.

13. Robinson JM, Ladd BO, Anderson KG. When you see it, let it be: urgency, mindfulness and adolescent substance use. Addict Behav 2014:39:1038-41.

14. Dabaghi P, Valipour H. Effectiveness of a multidimensional prevention program on reducing substance trends among young people. Addicta 2016;3:77-85.

15. Stratton KJ. Mindfulness-based approaches to impulsive behaviors. New School Psychol Bull 2006;4:49-71.

16. Bowen S, Witkiewitz K, Dillworth TM, Chawla N, Simpson TL, Ostafin BD, et al. Mindfulness meditation and substance use in an incarcerated population. Psychol Addict Behav 2006;20:343-7.

17. Dilbaz N, Aytekin Y. [Suicide ideation, behavior and suicide intent of alcohol dependent patients]. Bağımlılık Dergisi 2003;4:1-9. [Article in Turkish]

18. Ekici G, Savaş HA, Çıtak S. [The role of alcohol and substance usage history in committed suicides]. Bağımlılık Dergisi 2001;2:113-6. [Article in Turkish]

19. Berglund $\mathrm{M}$, Öjehagen A. The influence of alcohol drinking and alcoholusedisorders on psychiatric disorders and suicidal behavior. Alcohol Clin Exp Res 1998;22:333S-45S.

20. Tel H, Uzun S. [Social support and coping with stress in patients who were accepted to the emergency room with the suicide]. Anadolu Psikiyatri Derg 2003;4:151-8. [Article in Turkish] 21. Yılmaz Ö. Alkol bağımlısı olan erkeklerde kişilik özellikleri, stresle başa çıkma tarzları, intihar olasılığı ve depresif belirti düzeyinin incelenmesi Yüksek Lisans Tezi, Ankara: Hacettepe Üniversitesi Sosyal Bilimler Enstitüsü, Psikoloji Anabilim Dalı, 2012. 